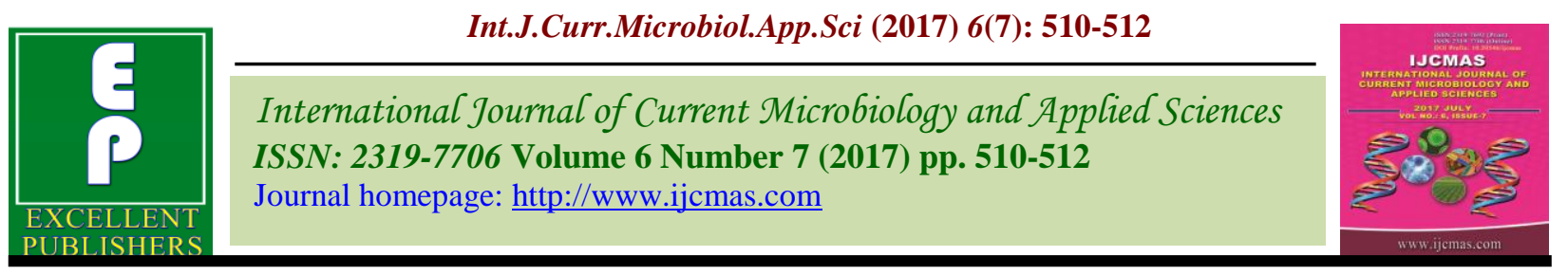

Original Research Article

https://doi.org/10.20546/ijcmas.2017.607.061

\title{
Evaluation of Hormonal Treatment Protocol and Improved Nutritional Therapeutic Management Practices for Inducing Heat in Anestrus Cows
}

\author{
Pankaj Lawania $^{1}$, Suresh Chandra Jingar ${ }^{2 *}$, A.K. Roy ${ }^{3}$, Deelip Kumar ${ }^{4}$ and Ajesh Kumar ${ }^{5}$ \\ ${ }^{1}$ A.H., KVK, Jalore, Rajasthan, India \\ ${ }^{2}$ A.H., KVK, Chittorgarh, Rajasthan, India \\ ${ }^{3}$ Animal Physiology, NDRI, Karnal, Haryana, India \\ ${ }^{4}$ Extension Education, KVK, Sirohi, Rajasthan, India \\ ${ }^{5}$ A.H., KVK, Bijapur, Karnataka, India \\ *Corresponding author
}

\begin{tabular}{|c|c|}
\hline & A B S T R A C T \\
\hline & \multirow{6}{*}{$\begin{array}{l}\text { Twenty adult anoestrus cows aged between } 6-10 \text { years were selected for the } \\
\text { experiment under field conditions. The cows were randomly divided into two } \\
\text { groups of ten animals each. Group- } 1 \text { cows received Duraprogen (17-a-hydroxy } \\
\text { progesterone- } 0.25 \mathrm{~g} / \mathrm{ml} \text { ) @ } 250 \mathrm{mg} \mathrm{i} / \mathrm{m} \text { followed by injection of Progynon depot } \\
\text { (Estradiol valerate- } 10 \mathrm{mg} / \mathrm{ml} \text { ) @ } 500 \mu \mathrm{I} / \mathrm{m} \text { after } 48 \mathrm{hrs} \text { of hydroxyl progesterone } \\
\text { injection, while group- } 2 \text { cows were given deworming by a broad spectrum } \\
\text { anthelmintic followed by the administration of trace minerals (Cyclomin-7, Pfizer } \\
\text { Animals Health India Ltd. @ } 1 \text { bolus/cow/day) and vitamins (Injection Intavita-H, } \\
\text { Intas Pharmaceutical for } 28 \text { days. The estrus was detected through visual } \\
\text { observation in the morning and evening which was confirmed by rectal } \\
\text { examination. The result indicated that } 80 \% \text { ( } 8 \text { cows) in group- } 2 \text { and } 60 \% \text { ( } 6 \text { cows) } \\
\text { in group- } 1 \text { exhibited heat symptoms after the treatment. In group- } 2,70 \% \text { cows } \\
\text { conceived following insemination while in group- } 1 \text { only } 50 \% \text { cows could } \\
\text { conceive. }\end{array}$} \\
\hline Keywords & \\
\hline $\begin{array}{l}\text { Hormonal } \\
\text { treatment, } \\
\text { Anestrus cows, } \\
\text { Cattle productivity }\end{array}$ & \\
\hline Article Info & \\
\hline $\begin{array}{l}\text { Accepted: } \\
\text { 04 June } 2017 \\
\text { Available Online: } \\
\text { 10 July } 2017\end{array}$ & \\
\hline & \\
\hline
\end{tabular}

\section{Introduction}

Cattle productivity depends largely on the reproductive efficiency and often measured by the number of offspring per breeding animal per unit time. Cows suffer mostly due to anestrus, which causes great loss to the economy of dairy farmers. A period of anoestrus following parturition is a normal physiological event but becomes abnormal when its duration extends more than the accepted average. It is one of the major problems in the development of animal husbandry sector in semiarid region, due to the scarcity of feed resources, lack of concentrate feeding and poor health coverage. It has been found that anovular cows can reduce the dairy herd profitability due to increased risk of culling and increased inseminations per conception (De Vries et al., 2006). Thus, effective treatment of an ovular cows, is likely to improve reproductive efficiency in a dairy herd and may increase profitability. Anoestrus is the most prevalent 
form of infertility encountered in bovines that varied from 30 to $>50 \%$ in Sirohi District of Southern Rajasthan. A systematic study on the induction of estrus is inevitable to improve the reproductive efficiency and fertility of bovines under field conditions.

Therefore, the present experiment was undertaken to evaluate the administration of $\mathrm{GnRH}$ and progesterone +Estrogen and improve the nutritional therapeutic management practices for inducing estrus in anestrous bovines and conception rate in the farmer's herd.

\section{Materials and Methods}

The experiment was conducted at the farmer's herds of the Krishi Vigyan Kendra adopted villages (Bapuda and Dokera) covered under "on farm trial" programmes. Twenty adult true anoestrus postpartum cows aged between 6-10 years were selected for the experiment. True anoestrus was confirmed due to the absence of corpus luteum or follicle on their ovaries by per rectum examination. The animals were maintained in loose housing system at farmer's door step. Wheat straw and homemade concentrate were fed and fresh clean water was offered adlib. The postpartum cows were randomly divided into two groups of ten cows each. Group-1 cows received Duraprogen (17-a-hydroxy progesterone- $0.25 \mathrm{~g} / \mathrm{ml}$ ) @ 250mg i $/ \mathrm{m}$ followed by injection of Progynon depot (Estradiol valerate-10mg/ml) @ $500 \mu \mathrm{I} / \mathrm{m}$ after $48 \mathrm{hrs}$ of hydroxyl progesterone injection, while group-2 cows were given deworming by a broad spectrum anthelmintic followed by the administration of trace minerals(Cyclomin-7, Pfizer Animals Health India Ltd.@1 bolus/cow/day) and vitamins (Injection Intavita-H, Intas Pharmaceutical for 28 days. The estrus was detected through visual observation in the morning and evening which was confirmed by rectal examination. The cattle in estrus were inseminated at 11 to
12 hrs intervals. Pregnancy was confirmed per-rectum after 55to 60 days of insemination.

\section{Results and Discussion}

The result indicated that $80 \%$ (8cows) in group-2 and $60 \%$ (6 cows) in group-1 exhibited heat symptoms after the treatment. In group-2, 70\% cows conceived following insemination while in group- 1 only $50 \%$ cows could conceive. The results observed in this study are similar to those reported by Saha et al., (2010). 45.16\% acyclic ewes came into estrus with $100 \%$ fertility after proper feeding, vitamin and mineral supplementation. In the present study high estrus induction and satisfactory conception rate were observed which could be due to combined effect of various trace minerals like copper, cobalt, zinc, magnese, iron, iodine and vitamins like $\mathrm{A}, \mathrm{D}_{3}, \mathrm{E} \&$ hormones which have positive effect on steroids synthesis, follicular growth and estrus. As the cows reach an improved energy and nutrient status, LH pulses increase and follicles grow to sufficient size resulting in estradiol production to cause the animal to come into estrus and ovulate (Beam and Butler, 1999). The treatment of anestrous cows before the start of breeding resulted in earlier conception than no treatment but had no effect on the final pregnancy rate (McDougall, (2010). There are several reports available on the influence of body condition score on conception rate (Schneider, 2004, Wade and Jones, 2004). The reason for the reduced conception rate in low body condition score might be due to the reduced gonadotropin releasing hormone $(\mathrm{GnRH})$.However, cows with good BCS in well-fed dairy farms have also found higher incidences of anovulation.

\section{Economics of treatment}

Total expenditure on 10 cows of group-1and group-2 was Rs. 5200/-and Rs. 3300/- 
respectively. Only six animals (Group-1) and eight animals (Group-2) came into estrus after the treatment. Improvement of nutrition and therapeutic management practices are helpful in bringing animals into heat. The calving of all anestrous cows treated under field conditions indicate the usefulness of nutritional or therapeutic management techniques in increasing milk production of farmer's herds for fetching more economic returns.

The objective of the present study was to induce estrus in anestrous cows for increasing the calving percentage in farmer's herd. Different protocols have been developed for estrus induction in cows but the information on cost effective, farmer-oriented and field applicable estrus induction protocol under semi-arid environment is scanty. The results indicate that deworming, proper concentrate, vitamins and minerals supplementation can be effectively used for the induction of estrus in cows under field conditions.

\section{References}

Beam, S.W., and W.R. Butler. 1999. Effects of energy balance on follicular development and first ovulation in postpartum dairy cows. J. Reprod. Fertil. 54(Suppl):411-424.

De Vries, A., M.B. Crane, J.A. Bartolome, P. Melendez, C.A. Risco, and L.F. Archbald. 2006. Economic comparison of timed artificial insemination and exogenous progesterone as treatments for ovarian cysts. J. Dairy Sci. 89:30283037.

McDougall, S. (2010) Effects of treatment of anestrous dairy cows with gonadotropin-releasing hormone, prostaglandin, and progesterone. J.Dairy Sci. 93(5): 1944-59.

Saha, S., Kumar, Davendra, Naqvi, S.M.K. and Mann, J.S. (2010). Estrus induction in acyclic ewes under field condition of semiarid region of Rajasthan. Indian Journal of small Ruminants, 16(1):111112.

Schneider, J.E. (2004). Energy balance and reproduction. Physiology and Behaviour. 81:289-317.

Wade, G.N. and Jones, J.E. (2004).Neuroendocrinology of nutrition infertility. American Journal of physiology- Regulative, integrative and comparative physiology. 287:R1277R1296.

\section{How to cite this article:}

Pankaj Lawania, Suresh Chandra Jingar, A.K. Roy, Deelip Kumar and Ajesh Kumar. 2017. Evaluation of Hormonal Treatment Protocol and Improved Nutritional Therapeutic Management Practices for Inducing Heat in Anestrus Cows. Int.J.Curr.Microbiol.App.Sci. 6(7): 510-512. doi: https://doi.org/10.20546/ijcmas.2017.607.061 